\title{
Retraction Note: Artificial intelligence system-based oasis soil water quality measurement and network marketing behavior analysis
}

\author{
Fagang $\mathrm{Hu}^{1}$
}

Published online: 22 November 2021

C) Saudi Society for Geosciences 2021

Retraction Note: Arabian Journal of Geosciences (2021) 14: 1478 https://doi.org/10.1007/s12517-021-07737-5

The Editor-in-Chief and the Publisher have retracted this article because the content of this article is nonsensical. The peer review process was not carried out in accordance with the Publisher's peer review policy. The author has not responded to correspondence regarding this retraction.

The original article can be found online at https://doi.org/10.1007/ s12517-021-07737-5.

Fagang $\mathrm{Hu}$

hufagang8485@163.com

1 Business School, Suzhou University, Suzhou 234000, Anhui, China 